\title{
Pemanfaatan Lumpur Lapindo sebagai Bahan Baku Pembuatan Genteng dengan Variasi Suhu Pembakaran
}

\section{Utilization of Lapindo Mud as Raw Material for Ceramic Roof Tile by Varying Burning Temperature}

\author{
Wasir Nuri $^{\mathrm{a}^{*}}$ dan Dyah Tri Retno ${ }^{\mathrm{a}}$ \\ Teknik Kimia, FTI, UPN "Veteran” Yogyakarta \\ Jalan SWK 104 (Lingkar Utara), Condongcatur, Yogyakarta, 55283
}

\section{Artikel histori :}

Diterima 1 Juni 2015

Diterima dalam revisi 14 Juni 2015 Diterima 1 Juli 2015 Online 09 Juli 2015

\begin{abstract}
ABSTRAK: Semburan lumpur Lapindo mengeluarkan lumpur yang volumenya sangat besar. Lumpur tersebut menggenangi areal persawahan, pemukiman dan kawasan industry sampai saat ini semburan belum berhenti tetapi lumpur belum dimanfaatkan. Oleh sebab itu dicoba memanfaatkan lumpur Lapindo yang sangat banyak itu untuk dibuat genteng. Lumpur mengandung oksida silika 55,4\%, alumina $16,1 \%$ dan besi $8,9 \%$ dengan komposisi tersebut kemungkinan lumpur dapat dibuat genteng. Lumpur yang sudah kering dihaluskan menjadi ukuran butir 80 mesh selanjutnya ditambah air sampai plastis. Lumpur yang sudah plastis dicetak dengan ukuran $6 \times 3 \times 3 \mathrm{~cm}$ kemudian dikeringkan menggunakan udara sekitar. setelah kering sampel dibakar menggunakan furnance pada suhu bervariasi mulai 500 sampai $900^{\circ} \mathrm{C}$, setelah dingin sampel diuji kuat tekan, modulus patah dan daya serap terhadap air. Hasil penelitian menunjukkan bahwa semakin tinggi suhu pembakaran diperoleh kuat tekan yang semakin besar dan daya serap air semakin kecil. Kuat tekan paling besar142 kg/ $\mathrm{cm}^{2}$ dan daya serap air paling kecil $0,06 \mathrm{~g} / \mathrm{cm}^{2}$ pada suhu $900^{\circ} \mathrm{C}$. Pada suhu pembakaran 500 sampai $700^{\circ} \mathrm{C}$ modulus patah turun dari 72,78 menjadi $41,81 \mathrm{~kg} / \mathrm{cm}^{2}$ sedangkan pada 700 sampai $900^{\circ} \mathrm{C}$ modulus patah naik menjadi $126,7 \mathrm{~kg} / \mathrm{cm}^{2}$. Hasil terbaik diperoleh pada suhu pembakaran $800^{\circ} \mathrm{C}$ dengan modulus patah sebesar $103,18 \mathrm{~kg} / \mathrm{cm}^{2}$ dan daya serap air 0,08 $\mathrm{g} / \mathrm{cm}^{2}$. Hasil tersebut memenuhi sarat sebagai genteng tipe I menurut SII.0027-81 UDC. 666.74 .
\end{abstract}

Kata Kunci: Lumpur Lapindo; genteng; variasi suhu.

ABSTRACT: Lapindo mudflow issued a very large volume of mud. The mud flooded rice fields, residential and industrial area to date has not been stopped but the mud bursts untapped yet. Therefore, attempted use Lapindo mud very much it to be made tile. Sludge containing $55.4 \%$ silica oxide, alumina $16.1 \%$ and $8.9 \%$ iron with the composition of the possibility of mud can be created tile roof. Dried mud that has been mashed into the grain size of 80 mesh, then water added until plastic. Mud that has plastic printed with size $6 \times 3 \times 3 \mathrm{~cm}$ and then dried using ambient air. After the dried samples were burned using a furnace at temperatures varying from 500 to $900^{\circ} \mathrm{C}$, after chilling the samples tested compressive strength, fracture modulus and water absorption. The results showed that the higher the combustion temperature obtained greater compressive strength and less water absorption. Most compressive strength is $142 \mathrm{~kg} / \mathrm{cm}^{2}$ and smallest water absorption is $0.06 \mathrm{~g} / \mathrm{cm}^{2}$ at a temperature of $900^{\circ} \mathrm{C}$. At combustion temperatures of 500 to $700^{\circ} \mathrm{C}$ fracture modulus down from 72.78 to $41.81 \mathrm{~kg} / \mathrm{cm}^{2}$ while at 700 to $900^{\circ} \mathrm{C}$ fracture modulus rose to $126.7 \mathrm{~kg} / \mathrm{cm}^{2}$. The best results obtained on the combustion temperature at $800^{\circ} \mathrm{C}$ with fracture modulus $103.18 \mathrm{~kg} / \mathrm{cm}^{2}$ and water absorption $0.08 \mathrm{~g} / \mathrm{cm}^{2}$. These results satisfy roof tile as type I according SII.0027 UDC-81. 666.74.

Keywords: Lapindo mud; roof tile; temperature.

\section{Pendahuluan (Introduction)}

Pembangunan yang pesat sekarang ini menyebabkan meningkatnya kebutuhan bahan bangunan antara lain genteng. Semburan lumpur Lapindo di Sidoarjo merupakan tragedi, terjadi pada bulan Mei 2006 yang mana lumpur yang volumnya sangat besar menyembur di areal penduduk, sawah dan kawasan industry. Sampai sekarang lumpur tersebut belum dimanfaatkan.

Berdasarkan laporan Pertiwi dan Theresia (2012), Pengujian toksikologi di 3 laboratorium terakreditasi (Sucofindo, Corelab, Bogorlab) diperoleh kesimpulan

\footnotetext{
${ }^{*}$ Corresponding Authors: : (0274)486889

Email: wasirnuri_fti@yahoo.co.id
} 
bahwa lumpur Sidoarjo tidak termasuk limbah B3 baik untuk bahan anorganik seperti Arsen, Barium, Boron, Timbal, Raksa, Sianida Bebas dan sebagainya, maupun bahan organik seperti : Trichlorophenol, Chlordane, Chlorobenzene, Chloroform dan sebagainya. Hasil pengujian menunjukkan semua parameter bahan kimia di bawah baku mutu. Lebih lanjut, analisis bahan yang terkandung di dalam lumpur Lapindo ditunjukkan pada Tabel 1 .

Tabel 1. Komposisi Lumpur Lapindo (Pertiwi dan Theresia, 2012)

\begin{tabular}{cc}
\hline Komponen & Komposisi (\%) \\
\hline $\mathrm{SiO} 2$ & 53,08 \\
$\mathrm{AI} 2 \mathrm{O} 3$ & 18,27 \\
$\mathrm{Fe} 2 \mathrm{O} 3$ & 5,60 \\
$\mathrm{TiO} 2$ & 0,57 \\
$\mathrm{CaO}$ & 2,07 \\
$\mathrm{MgO}$ & 2,89 \\
$\mathrm{Na} 2 \mathrm{O}$ & 2,97 \\
$\mathrm{~K} 2 \mathrm{O}$ & 1,44 \\
Hilang pijar & 10,15 \\
SO3 & 2,96 \\
\hline
\end{tabular}

Berdasarkan Tabel 1, kandungan Silikat dan aluminium ini dapat digunakan sebagai bahan baku dalam pembuatan material keramik. Setyowati (2009) memanfaatkan lumpur lapindo sebagai campuran dalam pembuatan genteng keramik untuk meningkatkan kekuatan. Namun pada penelitian sebelumnya masih perlu dilakukan penelitian lebih lanjut agar hasil genteng dapat memenuhi standar.

Keramik adalah bahan atau produk dari bahan anorganik kecuali logam atau paduan logam dengan cara dipanaskan sampai terjadi peleburan sebagian atau seluruh bahan (Austin, 1996). Industri keramik digolongkan menjadi keramik halus, bahan bangunan dari tanah, gelas, email, bahan perekat mortel, bahan tahan api dan abrasive (Astuti, 1997).

Tanah liat pada umumnya dapat dijadikan bahan untuk membuat genteng, kualitas genteng tergantung jenis tanah liat dan cara pembuatannya. Macam-macam genteng adalah: Genteng tanah, genteng beton, genteng keramik, genteng asbes, genteng sirap dan genteng metel. Genteng yang baik adalah genteng yang mempunyai permukaan atas yang halus, tidak retak dan bentuknya seragam (SII, 1987). Standar genteng ditunjukkan pada Tabel.2

Tabel 2. Syarat mutu genteng (SII, 1987)

\begin{tabular}{lll}
\hline $\begin{array}{l}\text { Jenis } \\
\text { genteng }\end{array}$ & $\begin{array}{l}\text { Modulus } \\
\text { patah } \\
\left(\mathrm{kg} / \mathrm{cm}^{2}\right)\end{array}$ & $\begin{array}{l}\text { Daya serap } \\
\text { air } \\
\left(\mathrm{g} / \mathrm{cm}^{2}\right)\end{array}$ \\
\hline Tipe I & 52,1610 & 0,1 \\
Tipe II & 26,0820 & 0,1 \\
\hline
\end{tabular}

Pada penelitian ini akan digunakan variasi temperatur dalam pembuatan genteng keramik dari lumpur lapindo agar sesuai dengan standar SII.

\subsection{Bahan Penelitian}

Penelitian ini menggunakan bahan lumpur Lapindo dan air. Lumpur diambil di area lumpur Sidoarjo dan air diambil dari laboratorium teknologi keramik UPN "VETERAN" Yogyakarta.

\subsection{Alat Penelitian}

Alat yang digunakan pada penelitian ini adalah oven, jaw crusher, disk mill, ayakan, timbangan, alat pencetak, furnance, alat uji modulus patah dan alat uji kuat tekan.

\subsection{Pembuatan Keramik}

Penelitian ini diawali dengan penyiapan bahan baku. Lumpur dikeringkan di bawah sinar matahari, kemudian dihancurkan menggunakan jaw crusher sampai ukuran lebih kurang $0,5 \mathrm{~cm}$, dilanjutkan dengan disk mill sampai ukuran lolos 80 mesh.

Lumpur yang sudah dihaluskan ditambah air sampai plastis kemudiandicetak dengan ukuran $6 \times 3 \times 3 \mathrm{~cm}$. Benda uji kemudian dikeringkan menggunakan udara di sekeliling.

Selanjutnya dilakukan pembakaran benda uji. Benda uji yang sudah kering dibakar menggunakan furnance pada suhu bervariasi mulai 500 sampai $900^{\circ} \mathrm{C}$. Setelah benda uji dingin selanjutnya diuji kuat tekan, modulus patah dan daya serap air. Diagram alir jalanya penelitian ditunjukkan pada Gambar 1.

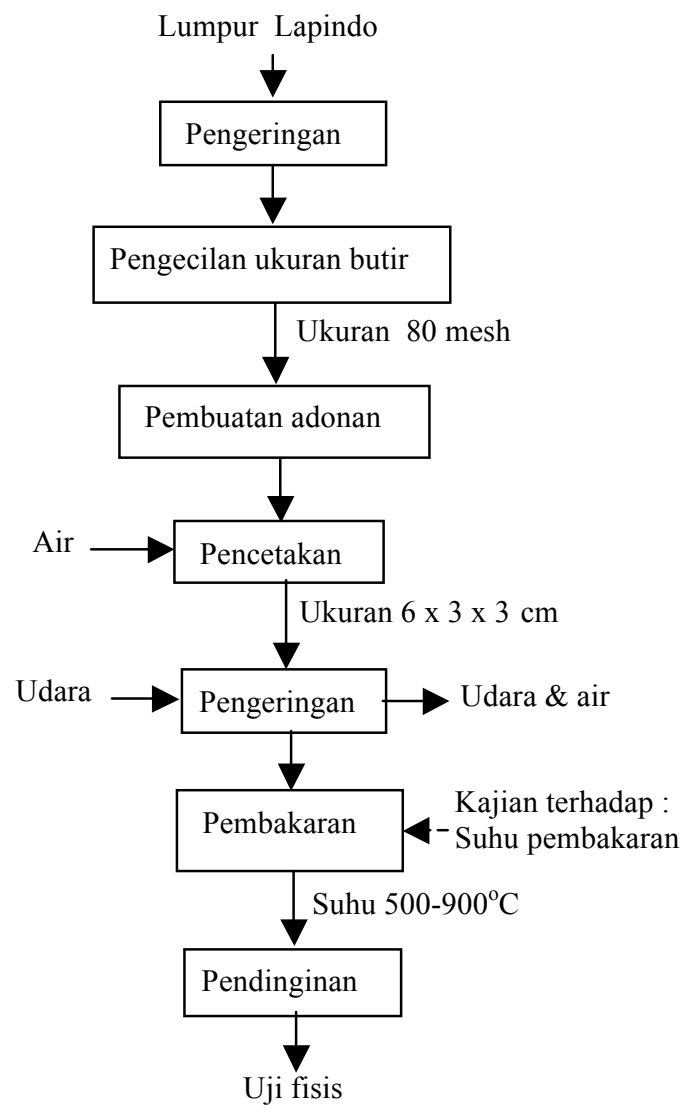

Gambar 1. Diagram Alir Penelitian

\section{Metode Penelitian}




\section{Hasil dan Pembahasan}

\subsection{Hasil Kuat Tekan}

Gambar 2 menunjukkan bahwa semakin tinggi suhu pembakaran menghasilkan kuat tekan yang semakin besar. Pada suhu $500^{\circ} \mathrm{C}$ kuat tekan sebesar $61,37 \mathrm{~kg} / \mathrm{cm}^{2}$ dan pada suhu $900{ }^{\circ} \mathrm{C}$ kuat tekan naik menjadi $142 \mathrm{~kg} / \mathrm{cm}^{2}$.

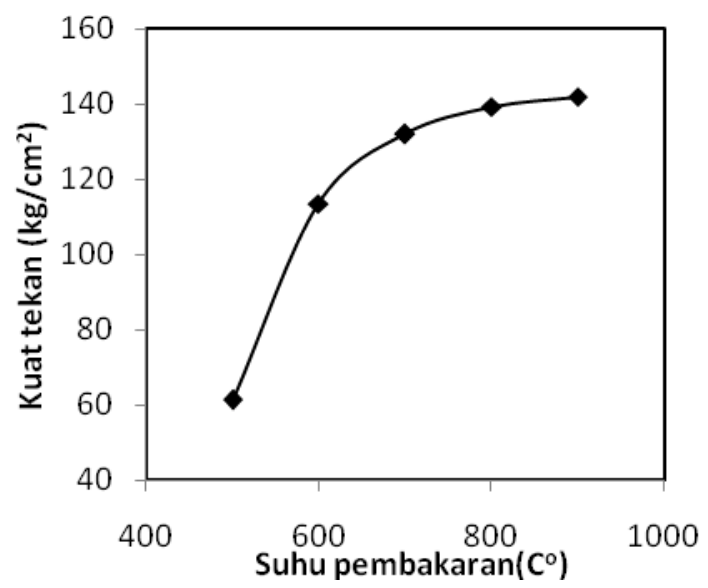

Gambar 2. Hubungan Suhu Pembakaran dan Kuat Tekan Genteng Keramik

Kuat tekan naik karena semakin tinggi suhu pembakaran oksida silika, oksida alumina dan oksida besi semakin banyak yang melebur sehingga benda uji menjdi keras. LumpurLapindo mengandung oksida silika 55,4\% oksida silika merupakan pembentuk gelas. Semakin tinggi suhu pembakaran semakin banyak oksida silika yang melebur sehingga benda uji menjadi keras oleh karena itu kuat tekan menjadi semakin besar.

\subsection{Modulus Patah}

Gambar 3 menunjukkan bahwa pada suhu $500^{\circ} \mathrm{C}$ sampai $700^{\circ} \mathrm{C}$ modulus patah benda uji semakin kecil dari 72,78 $\mathrm{kg} / \mathrm{cm}^{2}$ turun menjadi $47,81 \mathrm{~kg} / \mathrm{cm}^{2}$. Modulus patah turun karen pada suhu lebih rendah dari $700^{\circ} \mathrm{C}$ oksida alumina sudah melebur sedangkan oksida silika belum banyak yang melebur sehingga oksida alumina akan menggeser kedudukan silika dalam struktur tetrahidra atau oktohidra, selanjutnya oksida silika menjadi bebas, oleh karena itu struktur tetrahidra menjadi mudah pecah (Budworth, 1970), dengan demikian modulus patah benda uji menjadi rendah.

Pada suhu pembakaran diatas $700^{\circ} \mathrm{C}$ dihasilkan modulus patah semakin besar. Sebagai contoh pada suhu $900^{\circ} \mathrm{C}$ modulus patah naik menjadi $126,7 \mathrm{~kg} / \mathrm{cm}^{2}$. Modulus patah naik karena semakin tinggi suhu pembakaran akan semakin banyak oksida silika yang melebur. Pada suhu diatas $700^{\circ} \mathrm{C}$ oksida silika mulai melebur sehingga oksida silika bebas mulai terikat di dalam bentuk polimer oktohidra atau tertrahidrasilika, hal ini menyebabkan modulus patah benda uji menjadi semakin besar.

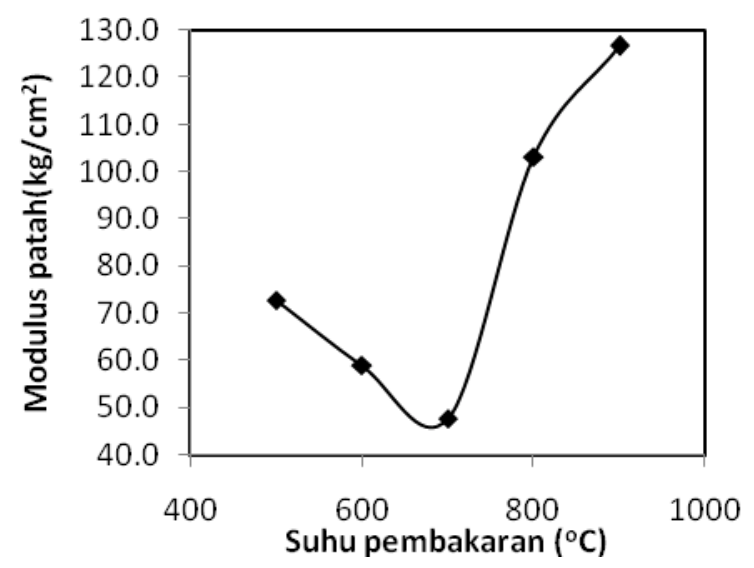

Gambar 3. Pengaruh Suhu Pembakaran terhadap Modulus Patah

\subsection{Daya Serap Air}

Gambar 4 menunjukkan bahwa semakin besar suhu pembakaran lumpur Lapindo menyebabkan daya serap air semakin kecil. Hal ini disebabkan semakin tinggi suhu pembakaran akan semakin banyak oksida silica, alumina dan besi yang melebur dengan meleburnya oksida-oksida tersebut akan menutup rongga atau pori diantara oksidaoksida tersebut sehingga daya serap air menjadi kecil.

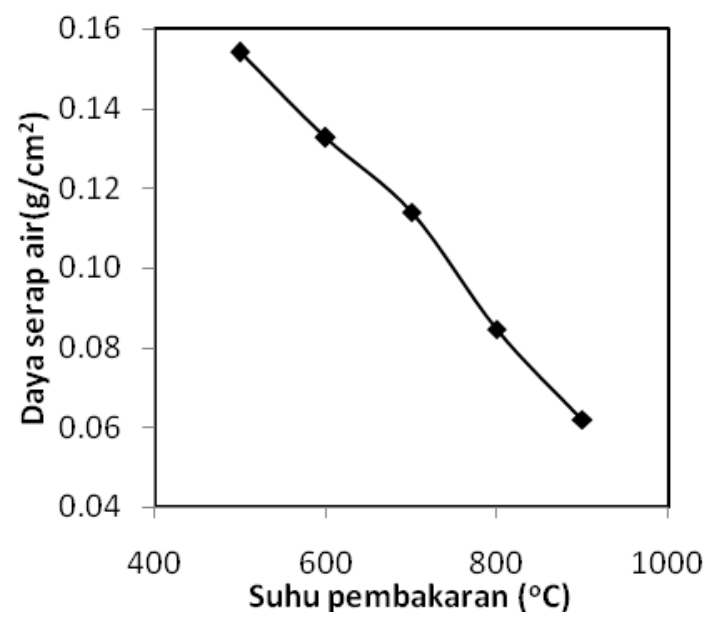

Gambar 4. Pengaruh Suhu Pembakaran terhadap Daya Serap Air

\subsection{Perbandingan Hasil Percobaan dengan Standar}

Pada penelitian ini diperoleh hasil genteng keramik yang terbuat dari lumpur lapindo yang telah sesuai standar SII.

Tabel 3. Perbandingan Hasil Percobaan dengan SII

\begin{tabular}{lllllll}
\hline Parameter & $\begin{array}{l}\text { SII } \\
\text { Tipe I }\end{array}$ & $\begin{array}{l}\text { SII } \\
\text { Tipe II }\end{array}$ & 600 & \multicolumn{5}{c}{ Penelitian ini $\left({ }^{0} \mathrm{C}\right)$} \\
\hline $\begin{array}{l}\text { Modulus } \\
\text { Patah } \\
\left(\mathrm{kg} / \mathrm{cm}^{2}\right)\end{array}$ & 52,16 & 26,08 & 59,09 & 47,81 & 103,18 & 126,7 \\
$\begin{array}{l}\text { Daya } \\
\text { serap air } \\
\left(\mathrm{g} / \mathrm{cm}^{2}\right)\end{array}$ & 0,1 & 0,1 & 0,13 & 0,11 & 0,08 & 0,06 \\
\hline
\end{tabular}


Tabel 3 menunjukkan bahwa pada operasi pembakaran temperatur di atas $800^{\circ} \mathrm{C}$ diperoleh hasil yang telah memenuhi standar SII tipe I.

\section{Kesimpulan}

Hasil penelitian dapat disimpulkan bahwa lumpur Lapindo dapat digunakan sebagai bahan membuat genteng. Benda uji dengan suhu pembakaran $800^{\circ} \mathrm{C}$ mempunyai modulus patah sebesar $103,18 \mathrm{~kg} / \mathrm{cm}^{2}$ dan daya serap air $0,08 \mathrm{~g} / \mathrm{cm}^{2}$. Hasil ini telah memenuhi standard sebagai genteng tipe I menurut SII. 0027-81 UDC. 666.74. dengan kuat tekan dan modulus patah tersebesar $142 \mathrm{~kg} / \mathrm{cm}^{2}$ dan $103,18 \mathrm{~kg} / \mathrm{cm}^{2}$ diperoleh pada suhu $900^{\circ} \mathrm{C}$ serta daya serap air terkecil sebesar 0,06 $\mathrm{gr} / \mathrm{cm}^{2}$ diperoleh pada suhu pembakaran $900^{\mathrm{O}} \mathrm{C}$.

\section{Daftar Pustaka}

Astuti, A., 1997, Pengetahuan Keramik, Gajah Mada University Pres, Yogyakarta.

Austin, G.T. 1984. Shreve's Chemical Process industries, $5^{\text {th }}$ ed., Mc Graw Hill, New York :

Budworth, D.W., 1970, An Introduction to Ceramic Science, $1{ }^{\text {st. }}$ ed., Pergamon Press, New York pp 59 $60,248-251$.

Pertiwi, D., Theresia Maria, C.A., 2012. Alternatif penggunaan lumpur lapindo sebagai pengganti sebagian semen untuk bahan bangunan. Jurnal Iptek.16(2): 67-73.

Setyowati, E.W., 2009. Lapindo sebagai campuran untuk meningkatkan kekuatan genteng keramik. Jurnal Rekayasa Sipil. 3(1): 29-35.

SII. 1991, 0021-78 UDC. 666.71,"Mutu dan Cara Uji Bata Merah Pejal', Dewan standardisasi Nasional DSN Jakarta.

SII. 1987, 0447-81 UDC. 666.74,"Mutu dan Cara Uji Genteng Beton", Dewan standardisasi Nasional DSN Jakarta. 